\title{
Monogenik Obezite Ön Tanısı ile İncelenen Hastaların Klinik, Laboratuvar ve Genetik Sonuçlarının Değerlendirilmesi
}

\section{Evaluation of Clinical, Laboratory and Genetic Results of Patients Who Examined with a Pre-Diagnosis of Monogenic Obesity}

\author{
İlkay Ayrancı (0000-0001-7898-5311), Gönül Çatı* (0000-0002-0488-6377), \\ Berna Eroğlu Filibeli (0000-0002-2696-0195), Elif Yiğit** (0000-0003-1326-9802), \\ Berk Özyılmaz ${ }^{\star \star \star}$ (0000-0003-2654-3698), Hayrullah Manyas (0000-0002-4775-2950), \\ Bumin N Dündar* (0000-0002-7506-061X) \\ Sağlık Bilimleri Üniversitesi, İzmir Tepecik Eğitim ve Araştırma Hastanesi, Çocuk Endokrinoloji Kliniği, İzmir, Türkiye \\ *Izmir Katip Çelebi Üniversitesi Tıp Fakültesi, Çocuk Endokrinoloji Anabilim Dalı, İzmir, Türkiye \\ **Sağlık Bilimleri Üniversitesi, İzmir Tepecik Eğitim ve Araşııma Hastanesi, Çocuk Sağlığı ve Hastalıkları Kliniği, İzmir, Türkiye \\ ***Sağlık Bilimleri Üniversitesi, İzmir Tepecik Eğitim ve Araştırma Hastanesi, Genetik Hastalıklar Tanı Merkezi, İzmir, Türkiye
}

\begin{abstract}
Anahtar kelimeler
Erken başlangıçlı, ailesel, monogenik obezite
\end{abstract}

Keywords

Early-onset, familial, monogenic obesity

Geliş Tarihi/Received : 10.08.2020

Kabul Tarihi/Accepted : 04.01.2021

DOI:10.4274/jcp.2021.0008

Yazışma Adresi (Sorumlu Yazar)/Address for Correspondence:

Dr. İlkay Ayrancı, Sağlık Bilimleri

Üniversitesi, İzmir Tepecik Eğitim ve

Araştırma Hastanesi, Çocuk Endokrinoloji

Kliniği, İzmir, Türkiye

\section{$\ddot{O} z$}

Giriş: Şiddetli ve erken başlangıçlı obezitenin genetik nedenlerinde monogenik obezite formları önemli bir yer tutmaktadır. Bu çalışmada, kliniğimizde monogenik obezite ön tanısı ile takip edilen olguların klinik ve moleküler genetik analiz sonuçlarının değerlendirilmesi amaçlanmıştır.

Gereç ve Yöntem: 2016-2018 yılları arasında kliniğimizde monogenik obezite ön tanısı ile moleküler genetik analiz yapılan olguların demografik, klinik ve biyokimyasal verileri geriye yönelik incelendi ve kaydedildi.

Bulgular: Çalışmaya toplam 47 obez olgu $(20 \mathrm{kız}, 39$ pubertal, ortalama yaş

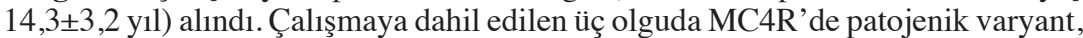
bir olguda veri tabanında patojen varyant olarak kabul edilmeyen LEPR'de heterozigot varyant saptandı. MC4R geninde sekans varyantı sıklığı \%6,4, LEPR geninde sekans varyantı sıklığ $\% 2,1$ olarak bulundu.

Sonuç: Çalışmamızda monogenik obezite şüphesiyle tetkik edilen çocukların $\% 8,5$ 'inde $(\mathrm{n}=4)$ sekans varyantı saptand. Bu olgularda obezite yaşamın ilk bir yılında gelişmişti ve ebeveynlerden en az birinde obezite mevcuttu. Bu nedenle, erken başlangıçlı obeziteye, ailesel obezite öyküsü eşlik ediyor ise ayırıcı tanıda öncelikle monogenik obezite formlarından olan MC4R defekti düşünülmelidir.

\begin{abstract}
Introduction:Monogenic forms of obesity have an important place in the genetic causes of severe and early-onset obesity. In this study, it was aimed to evaluate the clinical and molecular genetic analysis results of the cases followed up with a prediagnosis of monogenic obesity in our clinic.

Materials and Methods: The demographic, clinical and biochemical data of the patients had molecular genetic analysis with a pre-diagnosis of monogenic obesity in our clinic between 2016 and 2018 were retrospectively analyzed and recorded. Results: 47 obese cases (20 girls, 39 pubertal, mean age 14.3 \pm 3.2 years) were included in the study. Pathogenic variant in MC4R was detected in three cases, and heterozygous variant in LEPR, was not accepted as a pathogen variant in the database in one case. The frequency of sequence variants in the MC4R gene was $6.4 \%$, and the frequency of the sequence variants in the LEPR gene was $2.1 \%$.

Conclusions: In our study, $8.5 \%(n=4)$ sequence variant was found in children who were examined with suspicion of monogenic obesity. In these cases, obesity developed in the first year of life and at least one parent had obesity. Therefore, if early-onset obesity is accompanied by a family history of obesity, MC4R defect, one of the monogenic obesity forms, should be considered in differential diagnosis.
\end{abstract}




\section{Giriş}

Obezite, hem çevresel hem de genetik faktörler tarafından tetiklenen çok faktörlü bir hastalıktır. Yapılan çalışmalarda VKİ'deki varyasyonun yaklaşık üçte ikisinin genetik faktörler ile ilişkili olabileceği tahmin edilmektedir (1). Genom çalışmalarında obeziteye yatkınlı gösteren çeşitli varyantlar tanımlanmıştır. Ancak bu varyantlar obezitenin genetik temelinin sadece çok az bir kısmını açıklamaktadır (2). Son yirmi yılda yapılan genetik ve moleküler çalışmalar sonucunda, leptin tarafından yönlendirilen santral melanokortin yolu, vücut ağırlığını ve enerji homeostazını düzenleyen kritik sinyal sistemi olarak ortaya çıkmıştır. Leptin-melanokortin sinyalleşme düzeneğini oluşturan proteinleri kodlayan genlerde işlev kaybı, erken çocukluk döneminde hiperfaji ile karakterize ciddi obeziteye ve çeşitliendokrin ve immün bozukluklara neden olur (3-6). Leptin-melanokortin yolağındaki, leptin (LEP), leptin reseptörü (LEPR), melanokortin 4 reseptörü (MC4R), proprotein konvertaz subtilisin / keksin tip 1-2 (PCSK1/2) ve pro-opimelanokortin (POMC)'deki çok sayıda farklı nadir genetik varyantın, monogenik obezite formlarına neden olduğu gösterilmiştir. Ayrıca daha yakın zamanda bulunan, muhtemelen leptin bağımsız, vücut ağırlığ 1 ve enerji dengesinin düzenlenmesinde rol oynayan, beyin derive nörotropik faktör (BDNF) ve reseptörü, tropomyosin reseptör kinazı (NTRK2) ve transkripsiyon faktör single-minded 1 (SIM-1) gibi sistemlerden gelen sinyallerin de melanokortin yolununda etkili olabileceği bildirilmiştir (7-13).

Yapılan çalışmalarda şiddetli obezitesi olan hastaların sadece \%3-5'inde monogenik obezite formları tanımlanmıştır $(14,15)$. Monogenik obezite nedenlerin aydınlatılması eşlik edebilecek santral adrenal yetmezlik, hipogonadotropik hipogonadizm ve santral hipotiroidi gibi ek hastalıkların tanı ve tedavisi açısından önemlidir. Bu çalışmada, kliniğimizde monogenik obezite ön tanısı ile takip edilen olguların klinik ve moleküler genetik analiz sonuçlarının değerlendirilmesi amaçlanmıştır.

\section{Gereç ve Yöntem}

Kliniğimizde 2016-2018 yılları arasında monogenik obezite ön tanısı ile moleküler genetik analiz yapılan olguların demografik, klinik ve biyokimyasal verileri geriye yönelik incelendi ve kaydedildi. Hastaların antropometrik ölçümleri (ağırlık, boy, bel çevresi) ve kan basınçları kaydedildi. Neyzi verilerine göre ağırlık, boy, vücut kitle indeks persentilleri değerlendirildi ve VKİ-standart sapma skorlarları (SDS) hesaplandı (16). VKİ ağırlığın boyun metrekaresine bölünmesi ile [ağırlık/boy $2\left(\mathrm{~kg} / \mathrm{m}^{2}\right)$ ] hesaplandı.

\section{Çalışmaya Dahil Edilme Kriterleri}

(i) Şiddetli obezite (VKİ SDS $>2,5$ ), (ii) erken başlangıçlı obezite ( $<6$ yaş), (iii) ebeveynlerden en az birinde obezite ve (iv) ebeveynler arasında akrabalık bulunması kriterlerinden en az 2'sinin varlığ monogenik obezite için genetik analiz endikasyonu olarak kabul edildi.

\section{Çalışma Dışı Kalma Kriterleri}

Sendromik ve endokrin nedenli obez olgular çalışma dışı bırakıldı.

Kan basıncı ölçümleri yaşa, cinse ve boya göre 9095 persentil arasında ise prehipertansiyon, 95 persentil ve üzerinde ise hipertansiyon olarak değerlendirildi (17). Pubertal durum Tanner Evrelemesine göre değerlendirildi $(18,19)$.

\section{Laboratuvar Ölçümleri}

Obezite etiyolojisinin değerlendirilmesi amaciyla yapılan hasta yatışlarında gece açlığı sonrasında alınan, glukoz seviyesi, lipit profili [trigliserit (TG), total kolesterol (TK), düşük yoğunluklu lipoprotein kolesterol (LDL-C) ve yükssek yoğunluklu lipoprotein kolesterol seviyeleri (HDL-C)], insülin, sabah 08:00 kortizol seviyeleri ve $1,75 \mathrm{gr} / \mathrm{kg}$ dozda (maksimum 75 gr) glukoz yüklemesinden önce ve 30, 60, 90 ve 120. dakika sonra kan glukozu ve insülin konsantrasyonlarının ölçülmesiyle yapılan oral glukoz tolerans testinin (OGTT) sonuçları olgu rapor formuna kaydedildi. TK $\geq 200 \mathrm{mg} / \mathrm{dl}, \mathrm{TG} \geq 100 \mathrm{mg} / \mathrm{dL}$ (0-9 yaş), TG $\geq 130 \mathrm{mg} / \mathrm{dL}$ (10-19 yaş), LDL-C $\geq 130$ $\mathrm{mg} / \mathrm{dl}, \mathrm{HDK}-\mathrm{C}<40 \mathrm{mg} / \mathrm{dL}$ olan değerlerde hastalarda dislipidemi düşünüldü (20). İnsülin rezistansı indeksi homeostaz değerlendirme modeli (HOMA-IR) aşağıdaki denklem kullanılarak uygulandı: [açlık insülini (mU/L) x açlık glukozu (mmol/L) /22,5]. Bozulmuş açlık glukozu (açlık glukozu 100-125 mg/ dL), bozulmuş glukoz toleransı (2. saat glukoz 140-199 $\mathrm{mg} / \mathrm{dL}$ ) ve diyabet (açlık glukozu $\geq 126 \mathrm{mg} / \mathrm{dL}$ veya 2 . saat glukoz $\geq 200 \mathrm{mg} / \mathrm{dL}$ ) Amerikan Diyabet Derneği yönergelerine göre OGTT sırasında elde edilen glukoz 
seviyeleri ile tanımlandı (21). OGTT ile elde edilen pik insülin, 2. saat insülin ve toplam insülin değerleri sirasiyla $150(\mu \mathrm{U} / \mathrm{mL}), 75(\mu \mathrm{U} / \mathrm{mL})$ ve 300 'den $(\mu \mathrm{U} /$ $\mathrm{mL}$ ) yüksekse insülin rezistansı düşünüldü (22).

\section{Genetik Analiz}

Moleküler genetik analizler MC4R, LEP, LEPR ve $P O M C$ genlerinin yeni nesil dizi analizi (NGS) ile gerçekleştirildi. Bu amaçla NEXTflex Obezite-1 NGS Amplikon Paneli (BiooScientific) kullanıldı. Bu NGS paneli $L E P, L E P R, P O M C$ ve $M C 4 R$ genlerinin tüm kodlayan bölgelerini ve intron-ekzon bağlantı bölglerini kaplamaktaydı. Test, hedeflenmiş NGS yöntemi ile, MiSeqReagentNano Kit v2 (IlluminaInc.) kullanılarak bir IlluminaMiSeq NGS Sistemi (IlluminaInc.) üzerinde gerçekleştirildi. Ham veriler, GRCh37'nin (h19) referans genomuna göre "SEQ" varyant analiz yazılımı (Genomize) kullanılarak analiz edildi. Kaplam verileri SEQ varyant analizi yazılımının "CDS Kaplam \% Tablosu" ndan elde edildi. Her varyantın okuma derinliği SEQ varyant analiz yazılımından ve ayrica "IntegrativeGenomics Viewer" (IGV) (BroadInstitute) den kontrol edildi. Saptanan dizi varyantlarının ClinVAR kayıtları incelendi. "Benign" ve "Likely Benign" kayıtlara sahip varyantlar ekarte edildi. Bunlar dışındakilerin yorumları, Amerikan Tıbbi Genetik Koleji (ACMG) tarafından yayınlanan standartlara ve yönergelere göre yapıldı (23).

\section{İstatistiksel Analiz}

İstatistiksel analiz için SPSS 24,0 programı kullanıldı. Çalışmamızdaki parametreler için tanımlayıcı bir analiz yapılmıştır. Veriler kantitatif parametreler için ortalama standart sapma ve kategorik parametreler için yüzde olarak verilmiştir.

\section{Bulgular}

Çalışmaya toplam 47 obez olgu (20 kız, 39 pubertal, ortalama yaş 14,3 $\pm 3,2$ yıl) alındı. Olguların, $\% 85$ 'inde şiddetli obezite, \%51'inde erken başlangıçl1 obezite, \%17'sinde ebeveynler arasında akrabalık, $\% 63,8$ 'inde ebeveynlerden en az birinde obezite mevcuttu. Olguların \%55,3'ünde ailede diyabet öyküsü, \%63'ünde akantozis nigrikans, \%77'sinde stria saptandı. Olguların antropometrik ve laboratuvar özellikleri Tablo 1'de özetlenmiştir. Çalışmaya dahil edilen beş olguda bozulmuş açlık glukozu, beş olguda bozulmuş glukoz toleransı (bir olgu MC4R), bir olguda diyabet, \%46,8'inde TG, \%27,7'sinde total kolesterol, \%17'sinde LDL-K yüksekliği, \% 14,9'unda HDL-K düşüklüğü saptandı. Olguların \%44,7'sinde hipertansiyon, \%27,7'sinde prehipertansiyon bulundu. Çalışmaya dahil edilen üç olguda MC4R'de patojenik varyant, bir olguda veri tabanında patojen varyant olarak kabul edilmeyen LEPR'de heterozigot varyant saptand1. MC4R geninde sekans varyantı sıklığ $1 \% 6,4$, LEPR geninde sekans varyantı sıklığı \%2,1 olarak bulundu. Sekans varyantı saptanan olguların klinik ve demografik özellikleri Tablo 2'de özetlenmiştir.

\section{Tartışma}

Obezitenin genetik nedenleri; monogenik obezite (leptin-melanokortin yolağında bulunan tek bir gen mutasyonunun neden olduğu), sendromik obezite (nörogelişimsel anormallikler ve diğer organ / sistem malformasyonları gibi diğer fenotiplerle ilişkili şiddetli obezite), poligenik obezite (kilo alımını teşvik eden bir ortamda artan çok sayıda genin kümülatif katkısından kaynaklanan) olarak sinıflandırılabilir (24). Monogenik obezite için tanımlanan genlerin çoğu, iştah ve ağırlık düzenleyici sistemleri bozar. Çoğu mutasyon, fenotipin ortaya çıkması için homozigot veya compound heterozigot formda genin iki disfonksiyonel kopyasını gerektirir. MC4R, beynin iştah regülasyonunda yer alan yüksek oranda hipotalamusta eksprese edilen G-protein bağlı, yedi transmembran bölümden oluşan bir reseptördür (25). Kemirgen çalışmaları, MC4R'nin POMC'den üretilen yüksek afiniteli ligand olan alfa melonosit stimulan hormon ( $\alpha$-MSH) ile bağlanmasının beslenmeyi inhibe ettiğini göstermektedir (26). Genellikle dominant daha nadir olarak da resesif formda MC4R'deki mutasyonlar, farklı popülasyonlarda \%0,5-6 arasında prevalans ile kalıtsal erken başlangıçlı obezitenin en yaygın nedeni olarak gösterilmektedir (27-31). 2019 yılında ülkemizde erken başlangıçlı, non-sendromik obezitesi olan 105 hastanın genetik sonuçlarının değerlendirildiği bir çalışmada ise 2 tanesi yeni, 4 tanesi daha önce tanımlanmış olan, $M C 4 R$ geninde 6 mutasyon saptamıştır (32). Ülkemizde yine erken başlangıçlı obezitesi olan hastaların incelendiği diğer bir çalışmada ise $M C 4 R$ genindeki sekans varyant sıklığ $\% 8,6$ olarak bildirilmiştir (33). Çalışmamızda da literatür ile uyumlu olarak sekans varyant sıklığ 
en sık $\% 6,4$ oran ile $M C 4 R$ geninde saptanmıştır. Saptanan tüm varyantlar heterozigot olup literatürde patojenik olarak bildirilmiştir. Ayrıca tüm MC4R olgularında özgeçmişte erken başlangıçlı obezite öyküsü bulunurken, soygeçmişlerinde de ailede obezite öyküsü mevcuttur.

Leptin, esas olarak adipositler tarafından vücudun enerji durumunu bildirmek için salgılanan bir sitokindir ve işlevini hipotalamusta bir tokluk sinyali olarak yerine getirir $(34,35)$. Kromozom 7q31.3 üzerinde bulunan LEP geni tarafından kodlanır (34). Konjenital leptin eksikliği resesif bir kalıtım gösterir ve ilk olarak birinci derece kuzen Pakistanlı bir aileden bir çerçeve kayması mutasyonu (c.398delG) sonucu oluşan iki morbid obez hastada tanımlanmıştır (36). Majör fenotipik belirtiler, normal doğum ağırlığından sonra hızlı kilo alımıdır ve bu da yoğun hiperfajinin neden olduğu ciddi erken başlangıçlı obeziteye neden olur (37). Ek olarak, bu çocukların bazılarında kusurlu T hücresi bağışıklığı nedeniyle ciddi bakteriyel enfeksiyonlar ve hipogonadotropik hipogonadizm görülebilir. $\mathrm{Bu}$ hastalarda oluşan protein değişikliği leptin hormonunun düşük hatta saptanamayan seviyelerine veya normal seviyelerde biyolojik aktivite kaybına yol açar $(38,39)$. Konjenital leptin eksikliği, yağlanmayı iyileştiren ve gonadal ve bağışıklık fonksiyonunu geri kazandıran rekombinant leptin tedavisi en önemli tedavi seçeneğidir (40).

LEPR'deki mutasyonlar, düşük serum seviyeleri olmadan leptin eksikliğine benzer fenotipe neden olabilir (41). Yeni nesil sekanslamanın kullanımı ile literatürdeki yapılan çalışmalarda erken başlangıçlı obezitesi olan popülasyonda \%2-3 oranında LEPR mutasyonun olduğu tahmin edilmektedir $(42,43)$. Leptin eksikliğinden farklı olarak, homozigot LEPR mutasyonları olan bireyler rekombinant leptin tedavisine uygun değildir (24). Bu çalışmamızda, bir olguda veri tabanında klinik önemi bilinmeyen,

Tablo 1. Çalışmaya dahil edilen olguların antropometrik ve laboratuvar özellikleri

\begin{tabular}{|c|c|c|c|}
\hline & Ortalama & Dağılım & Ortanca Değer \\
\hline Yaş (yıl) & $14,3 \pm 3,3$ & $6,3-18,8$ & 15,9 \\
\hline Obezite başlangıç yaşı (yıl) & $6,3 \pm 5,0$ & $0,1-15$ & 5 \\
\hline Pubertal/Prepubertal & $39 / 8$ & & \\
\hline (Erkek/Kız) & $27 / 20$ & & \\
\hline A ğırlık SDS & $4,0 \pm 1,4$ & $1,3-8,5$ & 3,9 \\
\hline Boy SDS & $0,22 \pm 1,6$ & $-4,4-2,7$ & 0,37 \\
\hline VKİ $\left(\mathrm{kg} / \mathrm{m}^{2}\right)$ & $38,9 \pm 7,0$ & $27,7-64,7$ & 37,0 \\
\hline VKİ-SDS & $3,5 \pm 0,6$ & $2,1-5,3$ & 3,5 \\
\hline Sistolik kan basıncı & $125,0 \pm 14,2$ & $100-164$ & 120 \\
\hline Diyastolik kan basıncı & $78,9 \pm 10,7$ & $50-110$ & 80 \\
\hline Açlık kan glukozu (mg/dL) & $90,9 \pm 10,1$ & $71-116$ & 90 \\
\hline Tokluk kan glukozu (mg/dL) & $119,4 \pm 51,9$ & $56-405$ & 113 \\
\hline Açlık insülin $(\mu \mathrm{IU} / \mathrm{L})^{*}$ & $25,1 \pm 16,1$ & $0,4-74,3$ & 21 \\
\hline HOMA-IR & $5,7 \pm 3,6$ & $0,08-17,4$ & 4,8 \\
\hline OGTT toplam insülin & $473,9 \pm 278,8$ & $150-1252$ & 459 \\
\hline $\operatorname{Kortizol}(\mu \mathrm{g} / \mathrm{dL})^{* *}$ & $12,0 \pm 4,8$ & $1,3-23,7$ & 11,7 \\
\hline Trigliserid (mg/dL) & $129,9 \pm 51,6$ & $53-296$ & 118 \\
\hline Total kolesterol (mg/dL) & $180,1 \pm 36,1$ & $123-331$ & 172 \\
\hline LDL-K (mg/dL) & $112,8 \pm 31,2$ & $68-208$ & 108 \\
\hline HDL-K (mg/dL) & $43,1 \pm 8,9$ & $26-66$ & 40 \\
\hline $\mathrm{ALT}(\mathrm{IU} / \mathrm{L})$ & $34,3 \pm 30,8$ & 13-199 & 23 \\
\hline
\end{tabular}


in silico analizde patojen olduğu tahmin edilen LEPR'de heterozigot varyant saptand1. LEPR geninde mutasyonlar, otozomol resesif kalitılır. Literatürde, bazı çalışmalarda heterozigot obez vakalar da bildirilmiş, heterozigot vakaların homozigot vakalara göre daha az obez olduğu ve daha geç obezite geliştirdiği belirtilmiştir (44). Literatürde bu hastaların bazılarında büyüme hormonu eksikliği ve hipotiroidi de tanımlanmıştır $(45,46)$. Hastamızda ise büyüme hormonu eksikliği veya tiroid fonksiyon testlerinde anormallik saptanmadi. Bununla birlikte MC4R mutasyonu olan hastalarımızda olduğu gibi bu hastamızda da erken başlangıçlı obezite ve ailede obezite öyküsü mevcuttu.

Monogenik obezitenin diğer bir nedeni olan POMC proteinindeki eksiklik, adrenokortikotropik hormon (ACTH), $\alpha$-MSH ve $\beta$-endorfinlerin bölünme ürünlerinin yokluğu ile sonuçlanır (47). $\alpha$-MSH'nin iştah düzenleme ve pigmentasyondaki ikili rolü nedeniyle, hastalardaki klasik prezentasyon kızıl saç, şiddetli obezite ve ACTH eksikliğinden kaynaklı santral adrenal yetmezliktir. Birkaç çalışmada, adrenal yetmezliği ve diğer klasik belirtileri olmayan, obezitesi olan bireylerde heterozigot POMC mutasyonlarının da bildirilmiştir $(48,49)$. Bazı çalışmalarda yeni bir melanokortin-4 reseptör agonisti Setmelanotid'in POMC eksikliği için terapötik potansiyele sahip olduğu gösterilmektedir (50). PCSK1/2, büyük prekürsör proteinleri matur biyoaktif ürünlere işleyen nöroendokrin konvertaz endoproteazlardır (51). PCSK1/2 aktivitesinin olmamas1, ciddi erken başlangıçlı obeziteye ek olarak, insülin işleme eksikliğinden kaynaklanan postprandiyal hipoglisemik halsizlik ile birlikte adrenal, gonadotropik, somatotropik ve tirotropik yetmezlik, ciddi malabsorbsiyona neden olan ciddi neonatal diyare ve santral diyabetes insipitusa neden olur (5256). Diğer bir monogenik obezite nedeni olan SIM1, 6q16 kromozomu üzerinde bulunan bir transkripsiyon faktörüdür ve iştahın kritik bir düzenleyicisi olan

\begin{tabular}{|c|c|c|c|c|}
\hline & $\begin{array}{l}\text { MC4R } \\
\text { (1. olgu) }\end{array}$ & $\begin{array}{l}\text { MC4R } \\
\text { (2. olgu) }\end{array}$ & $\begin{array}{l}\text { MC4R } \\
\text { (3. olgu) }\end{array}$ & $\begin{array}{l}\text { LEPR } \\
\text { (4.olgu) }\end{array}$ \\
\hline Yaş (y1l) & 7,99 & 10,94 & 9,12 & 16,4 \\
\hline Obezite başlangıç yaşı (yıl) & Yenidoğan & Yenidoğan & Yenidoğan & Yenidoğan \\
\hline Cinsiyet & Erkek & Kadın & Kadın & Erkek \\
\hline Puberte durumu & Prepubertal & Pubertal & Prepubertal & Pubertal \\
\hline Ailede obezite & Var & Var & Var & Var \\
\hline A ğırlık-SDS & 4,63 & 4,43 & 2,79 & 2,3 \\
\hline Boy SDS & 2,48 & 2,5 & 0,03 & $-1,25$ \\
\hline VKİ $\left(\mathrm{kg} / \mathrm{m}^{2}\right)$ & 34,8 & 36,2 & 29,2 & 35,3 \\
\hline VKİ-SDS & 3,8 & 3,45 & 2,89 & 2,7 \\
\hline Açlık kan glukozu (mg/dL) & 92 & 89 & 94 & 85 \\
\hline Tokluk kan glukozu (mg/dL) & 106 & 155 & 104 & 113 \\
\hline Açlık insulin $(\mu \mathrm{IU} / \mathrm{L})$ & 30,7 & 54,6 & 15,6 & 7,1 \\
\hline Tokluk insulin $(\mu \mathrm{IU} / \mathrm{L})$ & 85 & 302 & 144,4 & 78,4 \\
\hline OGTT toplam insülin $(\mu \mathrm{IU} / \mathrm{L})$ & 559 & 888 & 358 & 313 \\
\hline Trigliserid (mg/dL) & 119 & 170 & 117 & 93 \\
\hline Total kolesterol (mg/dL) & 189 & 175 & 195 & 157 \\
\hline LDL-K (mg/dL) & 139 & 110 & 124 & 98 \\
\hline HDL-K (mg/dL) & 26 & 31 & 48 & 40 \\
\hline HOMA-IR & 6,9 & 11,8 & 3,6 & 1,49 \\
\hline Sistolik kan basıncı (mmHg) & 110 & 117 & 105 & 120 \\
\hline Diyastolik kan basıncı (mmHg) & 70 & 92 & 70 & 80 \\
\hline
\end{tabular}


hipotalamusun paraventriküler çekirdeğinde ekprese edilir (57). SIM1'deki delesyonlar veya heterozigot mutasyonlar hiperfaji, gıda alımında dürtüsellik ve konsantrasyon bozukluğu, hafıza eksikliğii, duygusal değişkenlik veya otizm spektrum bozukluğu gibi nörodavranışsal özellikler ile ilişkilendirilmiştir $(11,58)$. Çalışmamızda, yeni nesil dizi analizi ile hastalarda POMC değerlendirilmiş ve hiçbir olguda mutasyon saptanmamıştır. $\mathrm{Bu}$ bulgu, POMC, gen mutasyonlarının çok nadir görüldüğünü ve tipik klinik bulguları olmayan olgularda rutin bakılmaması gerektiğini düşündürmüştür.

\section{Sonuç}

Sonuç olarak, çalışmamızda monogenik obezite şüphesiyle tetkik edilen çocukların \%8,5'ünde $(n=4)$ sekans varyantı saptand. Sekans varyantı saptanan olguların tamamında obezite yaşamın ilk bir yılında gelişmişti ve ebeveynlerden en az birinde obezite mevcuttu. Bu nedenle, erken başlangıçlı obeziteye ( $<1$ yaş), ailesel obezite öyküsü eşlik ediyor ise ayırıcı tanıda öncelikle monogenik obezite nedenlerinden MC4R defekti düşünülmelidir.

\section{Etik}

Etik Kurul Onayı: Kliniğimizde 2016-2018 yılları arasında monogenik obezite ön tanısı ile moleküler genetik analiz yapılan olguların demografik, klinik ve biyokimyasal verileri geriye yönelik incelendi ve kaydedildi.

Çıkar Çatışması: Yazarlar tarafından çıkar çatışması bildirilmemiştir.

Finansal Destek: Yazarlar tarafından finansal destek almadıkları bildirilmiştir.

\section{Kaynaklar}

1. Stunkard AJ, Harris JR, Pedersen NL, McClearn GE. The bodymass index of twins who have been reared apart. The New England journal of medicine. 1990;322(21):1483-7.

2. Locke AE, Kahali B, Berndt SI, Justice AE, Pers TH, Day FR, et al. Genetic studies of body mass index yield new insights for obesity biology. Nature. 2015;518(7538):197-206.

3. Cone RD. Anatomy and regulation of the central melanocortin system. Nature neuroscience. 2005;8(5):571-8.

4. El-Sayed Moustafa JS, Froguel P. From obesity genetics to the future of personalized obesity therapy. Nature reviews Endocrinology. 2013;9(7):402-13.

5. Walley AJ, Asher JE, Froguel P. The genetic contribution to non-syndromic human obesity. Nature reviews Genetics. 2009;10(7):431-42.
6. O'Rahilly S, Farooqi IS. Genetics of obesity. Philosophical transactions of the Royal Society of London Series B, Biological sciences. 2006;361(1471):1095-105.

7. Gray J, Yeo GS, Cox JJ, Morton J, Adlam AL, Keogh JM, et al. Hyperphagia, severe obesity, impaired cognitive function, and hyperactivity associated with functional loss of one copy of the brain-derived neurotrophic factor (BDNF) gene. Diabetes. 2006;55(12):3366-71.

8. Gray J, Yeo G, Hung C, Keogh J, Clayton P, Banerjee K, et al. Functional characterization of human NTRK2 mutations identified in patients with severe early-onset obesity. International journal of obesity (2005). 2007;31(2):359-64.

9. Yeo GS, Connie Hung CC, Rochford J, Keogh J, Gray J, Sivaramakrishnan $\mathrm{S}$, et al. A de novo mutation affecting human TrkB associated with severe obesity and developmental delay. Nature neuroscience. 2004; 7(11):1187-9.

10. Bonnefond A, Raimondo A, Stutzmann F, Ghoussaini M, Ramachandrappa S, Bersten DC, et al. Loss-of-function mutations in SIM1 contribute to obesity and Prader-Willi-like features. The Journal of clinical investigation. 2013;123(7):303741.

11. Ramachandrappa S, Raimondo A, Cali AM, Keogh JM, Henning $\mathrm{E}$, Saeed $\mathrm{S}$, et al. Rare variants in single-minded 1 (SIM1) are associated with severe obesity. The Journal of clinical investigation. 2013;123(7):3042-50.

12. Bariohay B, Roux J, Tardivel C, Trouslard J, Jean A, Lebrun B. Brain-derived neurotrophic factor/tropomyosin-related kinase receptor type B signaling is a downstream effector of the brainstem melanocortin system in food intake control. Endocrinology. 2009;150(6):2646-53.

13. Tolson KP, Gemelli T, Gautron L, Elmquist JK, Zinn AR, Kublaoui BM. Postnatal Sim1 deficiency causes hyperphagic obesity and reduced Mc4r and oxytocin expression. The Journal of neuroscience : the official journal of the Society for Neuroscience. 2010;30(10):3803-12.

14. Farooqi IS, O'Rahilly S. Mutations in ligands and receptors of the leptin-melanocortin pathway that lead to obesity. Nature clinical practice Endocrinology \& metabolism. 2008;4(10):56977.

15. Froguel P, Blakemore AI. The power of the extreme in elucidating obesity. The New England journal of medicine. 2008;359(9):8913.

16. Neyzi O, Bundak R, Gökçay G, Günöz H, Furman A, Darendeliler $F$, et al.Reference Values for Weight,Height, Head Circumference, and Body Mass Index in Turkish Children. Journal of clinical research in pediatric endocrinology. 2015;7(4):280-93.

17. Flynn JT, Kaelber DC, Baker-Smith CM, Blowey D, Carroll AE, Daniels SR, et al. Clinical Practice Guideline for Screening and Management of High Blood Pressure in Children and Adolescents. Pediatrics. 2017;140(3).

18. Marshall WA, Tanner JM. Variations in the pattern of pubertal changes in boys. Archives of disease in childhood. 1970;45(239):13-23.

19. Marshall WA, Tanner JM. Variations in pattern of pubertal changes in girls. Archives of disease in childhood. 1969;44(235):291-303.

20. Expert panel on integrated guidelines for cardiovascular health and risk reduction in children and adolescents: summary report. Pediatrics. 2011;128 Suppl 5(Suppl 5):S213-56.

21. 2. Classification and Diagnosis of Diabetes. Diabetes care. 2016;39 Suppl 1:S13-22. 
22. Valerio G, Licenziati MR, Iannuzzi A, Franzese A, Siani P, Riccardi $G$, et al. Insulin resistance and impaired glucose tolerance in obese children and adolescents from Southern Italy. Nutrition, metabolism, and cardiovascular diseases : NMCD. 2006;16(4):279-84.

23. Li MM, Datto M, Duncavage EJ, Kulkarni S, Lindeman NI, Roy $\mathrm{S}$, et al. Standards and Guidelines for the Interpretation and Reporting of Sequence Variants in Cancer: A Joint Consensus Recommendation of the Association for Molecular Pathology, American Society of Clinical Oncology, and College of American Pathologists. The Journal of molecular diagnostics : JMD. 2017;19(1):4-23.

24. Pennington AW. A reorientation on obesity. The New England journal of medicine. 1953;248(23):959-64.

25. Stunkard AJ, Sørensen TI, Hanis C, Teasdale TW, Chakraborty $\mathrm{R}$, Schull WJ, et al. An adoption study of human obesity. The New England journal of medicine. 1986;314(4):193-8.

26. Fan W, Boston BA, Kesterson RA, Hruby VJ, Cone RD. Role of melanocortinergic neurons in feeding and the agouti obesity syndrome. Nature. 1997;385(6612):165-8.

27. Farooqi IS, Yeo GS, Keogh JM, Aminian S, Jebb SA, Butler $\mathrm{G}$, et al. Dominant and recessive inheritance of morbid obesity associated with melanocortin 4 receptor deficiency. The Journal of clinical investigation. 2000;106(2):271-9.

28. Yeo GS, Farooqi IS, Aminian S, Halsall DJ, Stanhope RG, O'Rahilly S. A frameshift mutation in MC4R associated with dominantly inherited human obesity. Nature genetics. 1998;20(2):111-2.

29. Nowacka-Woszuk J, Cieslak J, Skowronska B, Majewska KA, Stankiewicz W, Fichna P, et al. Missense mutations and polymorphisms of the MC4R gene in Polish obese children and adolescents in relation to the relative body mass index. Journal of applied genetics. 2011;52(3):319-23.

30. Wangensteen T, Kolsgaard ML, Mattingsdal M, Joner G, Tonstad $\mathrm{S}$, Undlien D, et al. Mutations in the melanocortin 4 receptor (MC4R) gene in obese patients in Norway. Experimental and clinical endocrinology \& diabetes : official journal, German Society of Endocrinology [and] German Diabetes Association. 2009;117(6):266-73.

31. Stutzmann F, Tan K, Vatin V, Dina C, Jouret B, Tichet J, et al. Prevalence of melanocortin-4 receptor deficiency in Europeans and their age-dependent penetrance in multigenerational pedigrees. Diabetes. 2008;57(9):2511-8.

32. Akıncı A, Türkkahraman D, Tekedereli İ, Özer L, Evren B, Şahin $\dot{I}$, et al. Novel Mutations in Obesity-related Genes in Turkish Children with Non-syndromic Early Onset Severe Obesity: A Multicentre Study. Journal of clinical research in pediatric endocrinology. 2019;11(4):341-9.

33. Aykut A, Özen S, Gökşen D, Ata A, Onay H, Atik T, et al. Melanocortin 4 receptor (MC4R) gene variants in children and adolescents having familial early-onset obesity: genetic and clinical characteristics. European journal of pediatrics. 2020;179(9):1445-52.

34. Zhang Y, Proenca R, Maffei M, Barone M, Leopold L, Friedman JM. Positional cloning of the mouse obese gene and its human homologue. Nature. 1994;372(6505):425-32.

35. Zhang F, Basinski MB, Beals JM, Briggs SL, Churgay LM, Clawson DK, et al. Crystal structure of the obese protein leptin-E100. Nature. 1997;387(6629):206-9.
36. Montague CT, Farooqi IS, Whitehead JP, Soos MA, Rau $\mathrm{H}$, Wareham $\mathrm{NJ}$, et al. Congenital leptin deficiency is associated with severe early-onset obesity in humans. Nature. 1997;387(6636):903-8.

37. Funcke JB, von Schnurbein J, Lennerz B, Lahr G, Debatin KM, Fischer-Posovszky P, et al. Monogenic forms of childhood obesity due to mutations in the leptin gene. Molecular and cellular pediatrics. 2014;1(1):3.

38. Wabitsch M, Funcke JB, Lennerz B, Kuhnle-Krahl U, Lahr $\mathrm{G}$, Debatin KM, et al. Biologically inactive leptin and earlyonset extreme obesity. The New England journal of medicine. 2015;372(1):48-54.

39. Farooqi IS, Matarese G, Lord GM, Keogh JM, Lawrence E, Agwu C, et al. Beneficial effects of leptin on obesity, T cell hyporesponsiveness, and neuroendocrine/metabolic dysfunction of human congenital leptin deficiency. The Journal of clinical investigation. 2002;110(8):1093-103.

40. Farooqi IS, Jebb SA, Langmack G, Lawrence E, Cheetham CH, Prentice AM, et al. Effects of recombinant leptin therapy in a child with congenital leptin deficiency. The New England journal of medicine. 1999;341(12):879-84.

41. Farooqi IS, Wangensteen T, Collins S, Kimber W, Matarese G, Keogh JM, et al. Clinical and molecular genetic spectrum of congenital deficiency of the leptin receptor. The New England journal of medicine. 2007;356(3):237-47.

42. Saeed S, Bonnefond A, Manzoor J, Shabbir F, Ayesha H, Philippe $\mathrm{J}$, et al. Erratum: Genetic variants in LEP, LEPR, and MC4R explain $30 \%$ of severe obesity in children from a consanguineous population. Obesity (Silver Spring, Md). 2017;25(4):807.

43. Mazen I, El-Gammal M, Abdel-Hamid M, Farooqi IS, Amr K. Homozygosity for a novel missense mutation in the leptin receptor gene (P316T) in two Egyptian cousins with severe early onset obesity. Molecular genetics and metabolism. 2011;102(4):461-4.

44. Huvenne H, Le Beyec J, Pépin D, Alili R, Kherchiche PP, Jeannic $\mathrm{E}$, et al. Seven novel deleterious LEPR mutations found in earlyonset obesity: a $\Delta$ Exon6-8 shared by subjects from Reunion Island, France, suggests a founder effect. The Journal of clinical endocrinology and metabolism. 2015;100(5):E757-66.

45. Clément K, Vaisse C, Lahlou N, Cabrol S, Pelloux V, Cassuto D, et al. A mutation in the human leptin receptor gene causes obesity and pituitary dysfunction. Nature. 1998;392(6674):398-401.

46. Huvenne H, Dubern B, Clément K, Poitou C. Rare Genetic Forms of Obesity: Clinical Approach and Current Treatments in 2016. Obesity facts. 2016;9(3):158-73.

47. Krude H, Biebermann H, Luck W, Horn R, Brabant G, Grüters A. Severe early-onset obesity, adrenal insufficiency and red hair pigmentation caused by POMC mutations in humans. Nature genetics. 1998;19(2):155-7.

48. Lee YS, Challis BG, Thompson DA, Yeo GS, Keogh JM, Madonna ME, et al. A POMC variant implicates beta-melanocytestimulating hormone in the control of human energy balance. Cell metabolism. 2006;3(2):135-40.

49. Challis BG, Pritchard LE, Creemers JW, Delplanque J, Keogh $\mathrm{JM}$, Luan J, et al. A missense mutation disrupting a dibasic prohormone processing site in pro-opiomelanocortin (POMC) increases susceptibility to early-onset obesity through a novel molecular mechanism. Human molecular genetics. 2002;11(17):1997-2004.

50. Kühnen P, Clément K, Wiegand S, Blankenstein O, Gottesdiener $\mathrm{K}$, Martini LL, et al. Proopiomelanocortin Deficiency Treated 
with a Melanocortin-4 Receptor Agonist. The New England journal of medicine. 2016;375(3):240-6.

51. Jansen E, Ayoubi TA, Meulemans SM, Van de Ven WJ. Neuroendocrine-specific expression of the human prohormone convertase 1 gene. Hormonal regulation of transcription through distinct cAMP response elements. The Journal of biological chemistry. 1995;270(25):15391-7.

52. O'Rahilly S, Gray H, Humphreys PJ, Krook A, Polonsky KS, White A, et al. Brief report: impaired processing of prohormones associated with abnormalities of glucose homeostasis and adrenal function. The New England journal of medicine. 1995;333(21):1386-90.

53. Jackson RS, Creemers JW, Ohagi S, Raffin-Sanson ML, Sanders L, Montague CT, et al. Obesity and impaired prohormone processing associated with mutations in the human prohormone convertase 1 gene. Nature genetics. 1997;16(3):303-6.

54. Jackson RS, Creemers JW, Farooqi IS, Raffin-Sanson ML, Varro A, Dockray GJ, et al. Small-intestinal dysfunction accompanies the complex endocrinopathy of human proprotein convertase 1 deficiency. The Journal of clinical investigation. 2003;112(10):1550-60.

55. Farooqi IS, Volders K, Stanhope R, Heuschkel R, White A, Lank E, et al. Hyperphagia and early-onset obesity due to a novel homozygous missense mutation in prohormone convertase 1/3. The Journal of clinical endocrinology and metabolism. 2007;92(9):3369-73.

56. Frank GR, Fox J, Candela N, Jovanovic Z, Bochukova E, Levine J, et al. Severe obesity and diabetes insipidus in a patient with PCSK1 deficiency. Molecular genetics and metabolism. 2013;110(1-2):191-4.

57. Michaud JL, Rosenquist T, May NR, Fan CM. Development of neuroendocrine lineages requires the bHLH-PAS transcription factor SIM1. Genes \& development. 1998;12(20):3264-75.

58. Holder JL, Jr., Butte NF, Zinn AR. Profound obesity associated with a balanced translocation that disrupts the SIM1 gene. Human molecular genetics. 2000;9(1):101-8. 